\title{
MODELAGEM DA VAZÃO E ANÁLISE DO ESCOAMENTO NA ÁREA DE RECARGA DE UMA NASCENTE INSERIDA NA BACIA DO RIO VERDE
}

\author{
Israel Luiz da Silva \\ Graduando em Agronomia pela Universidade Vale do Rio Verde (UNINCOR), MG, Brasil \\ israelluiz07_07@hotmail.com \\ Alisson Souza de Oliveira \\ Pós-Doutorado em Análise de Tendências Climáticas na Precipitação e Temperatura do Ar \\ pela Universidade Federal de Lavras (UFLA), MG, Brasil \\ Professor de Agrometeorologia e Climatologia na Universidade Vale do Rio Verde \\ (UNINCOR), MG, Brasil \\ alissonso@hotmail.com \\ Rosângela Francisca de Paula Vitor Marques \\ Doutorado em Recurso Hídricos em Sistemas Agrícolas pela \\ Universidade Federal de Lavras (UFLA), MG, Brasil \\ roeflorestal@hotmail.com
}

\section{RESUMO}

Entender a dinâmica da água em áreas de recarga de nascentes é extremamente importante, pois são precursoras dos cursos d'água. Objetivou-se a caracterização da área de recarga da nascente F1 e a modelagem de sua vazão. Localiza-se na Fazenda Experimental UninCor em Três Corações, MG. Para a delimitação da área de recarga e obtenção da declividade foi utilizado o MDE SRTM com resolução espacial de $30 \mathrm{~m}$, para a classificação do uso e cobertura da terra utilizou-se uma imagem do CBERS-4. A vazão foi avaliada em associação a área de recarga, relevo e uso e cobertura da terra. Realizou-se o monitoramento semanal da vazão entre abril e setembro de 2019, avaliando-se o deflúvio, vazão média, rendimento específico e a modelagem da vazão. $O$ uso do solo predominante é a pastagem degradada (91,98\%). O relevo predominante é o ondulado $(83,20 \%)$, declividade média de $15,16 \%$ e altitude média de 935,8 m. A vazão no início do período de depleção $\left(Q_{t}\right)$

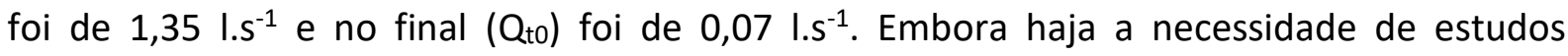
complementares, fica evidente a influência negativa do uso do solo na geração do escoamento, fatos comprovados com a relação $Q_{t} / Q_{t o}$ de apenas $5,20 \%$, aliado ainda ao coeficiente de depleção $\alpha$ igual a -0,02211. A precipitação total no período analisado foi de $929,28 \mathrm{~mm}$, o deflúvio total igual a $225,58 \mathrm{~mm}$ e a participação do deflúvio base no total precipitado (Db/P) foi de $24,27 \%$.

Palavras-chave: Uso e cobertura da terra. Relevo. Escoamento base. Período de depleção. 


\title{
FLOW MODELING AND ANALYSIS OF STREAMFLOW IN THE RECHARGE AREA OF A SPRING INSERTED IN THE RIO VERDE BASIN
}

\begin{abstract}
Understanding the dynamics of water in spring recharge areas is extremely important, as they are precursors to water courses. The objective was to characterize the recharge area of the F1 source and to model its flow. It is located at the Experimental Farm UninCor in Três Corações, MG. For the delimitation of the recharge area and obtaining the slope, the MDE SRTM with a spatial resolution of $30 \mathrm{~m}$ was used, for the classification of land use and land cover an image of CBERS-4 was used. The flow was evaluated in association with the area of recharge, relief and land use and coverage. Weekly flow monitoring was carried out between April and September 2019, evaluating the flow, average flow, specific yield and flow modeling. The predominant land use is degraded pasture (91.98\%). The predominant relief is undulating (83.20\%), with an average slope of $15.16 \%$ and an average altitude of $935.8 \mathrm{~m}$. The flow at the beginning of the depletion period (Qt) was 1.35 l.s-1 and non-final (Qt0) was 0.07 I.s-1. Although there is a need for complementary studies, it is evident the need for complementary studies of the soil in the generation of runoff, proven facts with a Qt / Qt0 ratio of only 5.20\%, allied to the $\alpha$ depletion coefficient equal to -0.02211 . The total participation in the analyzed period was $929.28 \mathrm{~mm}$, the total flow equal to $225.58 \mathrm{~mm}$ and the participation of the base flow in the precipitated total (Db / P) was $24.27 \%$.
\end{abstract}

Keywords: Land use and coverage. Land relief. Base flow. Depletion period.

Recebido: 23/06/2020. Aceito: 18/09/2020. 


\section{INTRODUÇÃO}

As nascentes são de extrema relevância nas bacias hidrográficas, pois a partir delas tem-se a origem dos cursos d'água que irão compor toda a bacia (GOMES et al., 2018). Para que a nascente seja considerada ideal, essa deve produzir água em qualidade e em quantidade, além de proporcionar uma vazão com pouca variação ao longo do tempo (LEAL et al., 2017).

Neste sentido, a preservação de suas áreas de recarga é de extrema importância, pois elas facilitaram o processo de infiltração da água no solo, recarga do lençol freático e, consequentemente, vazão em quantidade e qualidade na nascente. (LEAL et al., 2017)

Segundo a Lei Federal no 12.651 de 25 de maio de 2012 (BRASIL, 2012), Áreas de Preservação Permanente (APP) têm a função de preservar os recursos hídricos e as nascentes, sendo obrigatória a manutenção de um raio de 50 metros de vegetação nativa ao entorno da surgência das nascentes, buscando manter a biodiversidade, paisagem, estabilidade geológica, mantendo a qualidade de vida e evitando, assim, a falta da água para as próximas gerações (GOMES et al., 2018).

Devido ao manejo inadequado do uso do solo, seja por impudência ou desinformação da legislação vigente, algumas APPs das nascentes têm sido degradadas, diminuindo a capacidade de infiltração de água no solo e desequilibrando a sustentabilidade desses ecossistemas, podendo ocasionar até a seca dessas nascentes (ALVARENGA et al., 2016).

Assim sendo, a preservação das APPs das nascentes, principalmente as de cabeceiras, são extremamente importantes no tocante à produção de água em quantidade e qualidade, fato desconsiderado por grande parte dos usuários deste recurso tão importante (GOMES et al., 2018). Diante do exposto, objetivou-se neste trabalho a caracterização da área de recarga da nascente F1 e a modelagem de sua vazão localizada na Fazenda Experimental UninCor, Três Corações, MG. 
MODELAGEM DA VAZÃO E ANÁLISE DO ESCOAMENTO NA ÁREA DE RECARGA DE UMA NASCENTE INSERIDA NA BACIA DO RIO VERDE
Israel Luiz da Silva Alisson Souza de Oliveira Rosângela Francisca de Paula Vitor Marques

\section{MATERIAL E MÉTODOS}

\subsection{Caracterização da área de estudo}

A nascente estudada foi denominada F1, para diferenciar das demais presentes na área. Foi escolhida pois essa já foi a principal fonte de abastecimento de água para a propriedade. Está inserida na bacia hidrográfica do Rio Verde (GD4) na Fazenda Experimental UninCor no município de Três Corações, no Sul de Minas Gerais. Sua localização é coordenada UTM 476403,17m E, 7597626,30m S (FIGURA 1).

Figura 1 - Área de recarga da nascente F1.

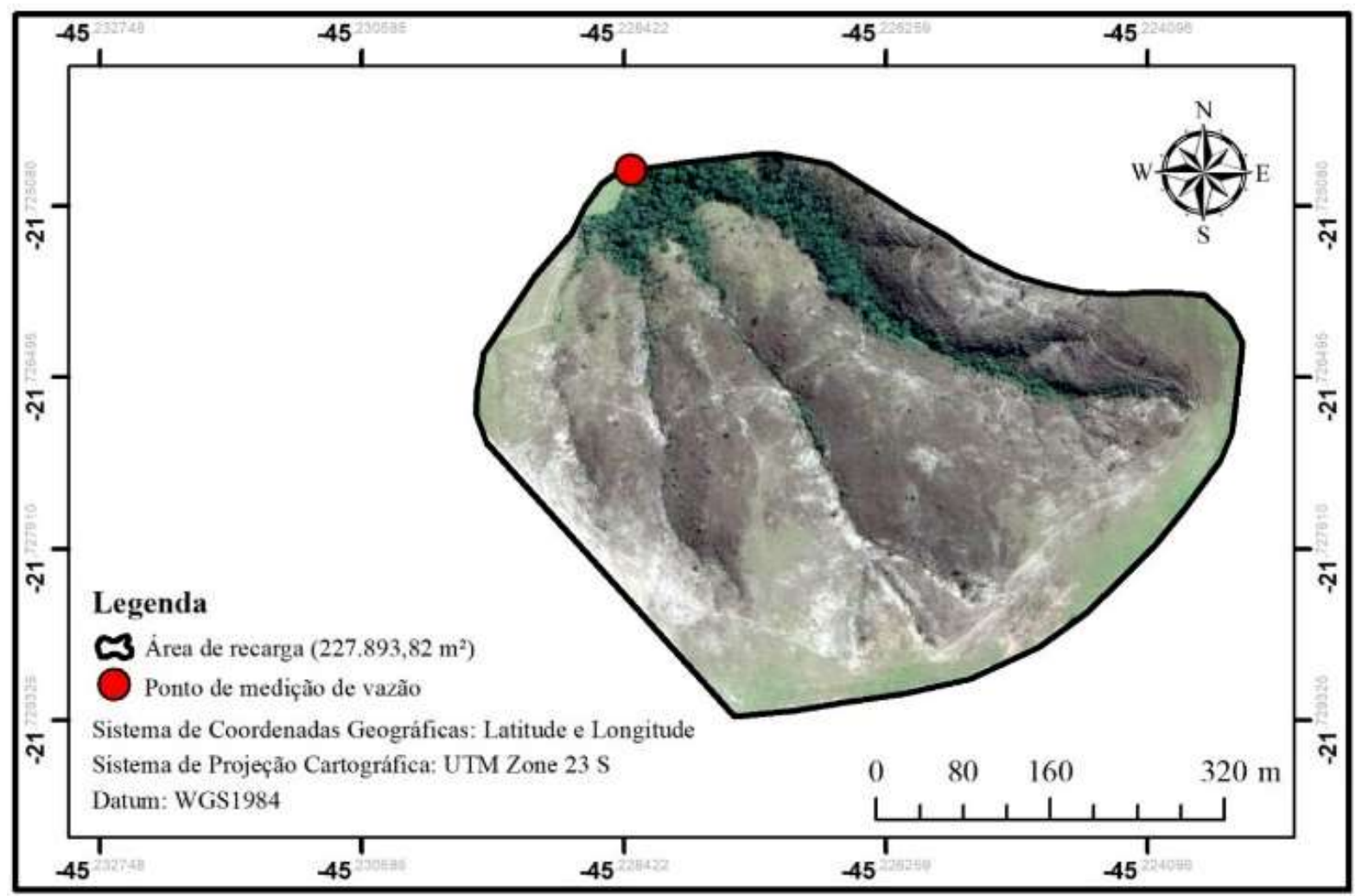

Fonte: Autor (2020).

\subsection{Delimitação da área de recarga da nascente F1}

Para a delimitação da área de recarga e obtenção da declividade foi utilizado o Modelo Digital de Elevação (MDE) Shuttle Radar Topography Mission (SRTM) com resolução espacial de $30 \mathrm{~m}$. 
Para a delimitação da área de recarga, no software QGIS $^{\circledR} 3.10$, foram realizados os seguintes processamentos: preenchimento das possíveis depressões no MDE com a utilização da ferramenta fill sinks; posteriormente a obtenção da direção de fluxo com a ferramenta flow direction; na sequência o fluxo acumulado (flow accumulation), possibilitando desta maneira a utilização da ferramenta watershed, delimitando-se a bacia hidrográfica (DIAS et al., 2004 apud SOBRINHO et al., 2010).

\subsection{Classificação do Uso e Cobertura da Terra}

O uso e cobertura da terra foi obtido com a utilização de imagens do satélite sino brasileiro CBERS-4 sensor MUX com resolução espacial de 20 m do mês de setembro de 2019. Após a composição RGB foi realizada a fusão da imagem RGB com uma imagem pancromática com resolução espacial de $5 \mathrm{~m}$. Este processamento, conhecido como fusão imagens (Pansharpened), permite a obtenção de uma imagem RGB com resolução espacial de $5 \mathrm{~m}$, melhorando o processo de classificação do uso do solo. A geração da imagem RGB e a fusão foram feitas no software QGIS ${ }^{\circledR} 3.10$.

A classificação do uso do solo foi feita no software Envi ${ }^{\circledR}$. Foi realizada a classificação supervisionada pelo método Máxima Verossimilhança (COHENCA; CARVALHO, 2015).

\subsection{Monitoramento e Modelagem da Vazão no Período de Recessão}

A vazão foi monitorada utilizando-se de um medidor do tipo vertedor retangular com constrição lateral construído em chapa metálica. As medições foram realizadas semanalmente entre os meses de abril e setembro de 2019. A vazão medida correspondeu sempre ao escoamento de base (surgência da nascente), ou seja, não houve contribuição do escoamento superficial direto.

O deflúvio gerado pela nascente no período da depleção foi estimado a partir da integração numérica dos dados de vazão. Também foi calculada a vazão específica.

Para o período de abril a setembro (período de seca), foi estimada a equação de decaimento das vazões, Equação (1) conforme "Fórmula de Maillet" (CASTANY, 1967), cujo coeficiente foi ajustado utilizando-se a ferramenta SOLVER - Excell ${ }^{\circledR}$, método de Newton 
Raphson e, para verificar a qualidade do ajuste, foi obtido o coeficiente de determinação $\left(R^{2}\right)$,

$$
\begin{aligned}
& \text { Equação } 1 \text { - Equação. } \\
& Q_{t}=Q_{t 0} * e^{\left(-\pi\left(t-t_{0}\right)\right)} \\
& \text { Fonte: Castany (1967). }
\end{aligned}
$$

Sendo:

Qt = é a vazão da nascente no tempo $t\left(\right.$ L.S $\left.^{-1}\right)$;

$\alpha=$ é o coeficiente de depleção da vazão da nascente $\left(\operatorname{dia}^{-1}\right)$, representa a taxa de decaimento da vazão com o tempo. É um índice que depende principalmente da geologia, tipo de solo e geomorfologia (USAE, 1999; COSTA; BACELLAR, 2010), sendo, portanto, característico de cada área de drenagem;

t0 = é o dia Juliano (DJ - dias corridos a partir de primeiro de janeiro de cada ano), correspondente ao início do período de depleção do escoamento subterrâneo e t é o dia Juliano para o qual se deseja estimar a vazão, sendo que $t>=t_{0}$, considerou-se $o$ início do período de depleção o DJ 96, correspondendo à data de 06/04/2019.

\subsection{Análise do Escoamento}

Para o melhor entendimento do regime de escoamento na área de recarga da nascente F1, com base nos dados de vazão no período monitorado entre abril de 2019 e fevereiro de 2020, calculou-se o deflúvio total, os deflúvios no período de recessão, no período de recarga, e suas participações em relação ao total precipitado.

O deflúvio foi calculado por intermédio da integração numérica tendo como base os valores médios de vazão entre duas leituras consecutivas. 


\section{RESULTADOS}

\subsection{Caracterização do Uso e Cobertura da Terra na área de recarga da nascente}

A área de recarga da nascente $\mathrm{F} 1$ possui $227.893,82 \mathrm{~m}^{2}$, sendo $91,98 \%$ ocupados por pastagem degradada $\left(209.616,74 \mathrm{~m}^{2}\right)$ e o restante $(8,02 \%)$ ocupados com mata nativa $\left(18.277,08 \mathrm{~m}^{2}\right)$. Hidrologicamente, o processo de recarga do lençol freático é reduzido drasticamente em áreas com predomínio de pastagem degradada, visto que ocorre um maior escoamento superficial direto, diminuindo o tempo de oportunidade para que a água sofra o processo de infiltração e consequente recarga. Resultados obtidos por Gaspar, Campos e Cadamuro (2007), corroboram com esta afirmação. No trabalho, avaliaram o potencial de infiltração de água no solo em diferentes usos e concluíram que dentre os usos que proporcionam as menores taxas de infiltração se encontra a pastagem degradada.

Na Figura 2 é apresenta a distribuição espacial do uso e ocupação da terra na área de recarga. Fica evidente que a mata nativa além de ocupar pequena porção da área, possui uma distribuição muito desequilibrada, restringindo-se, em grande parte, próximo à surgência da nascente. Esta distribuição, além de não contribuir eficientemente para o processo de recarga do lençol freático, não é capaz de impedir a entrada de sedimentos próximo à surgência da nascente, fato observado em campo. 
Figura 2 - Distribuição espacial do uso e ocupação da terra na área de recarga da nascente F1.

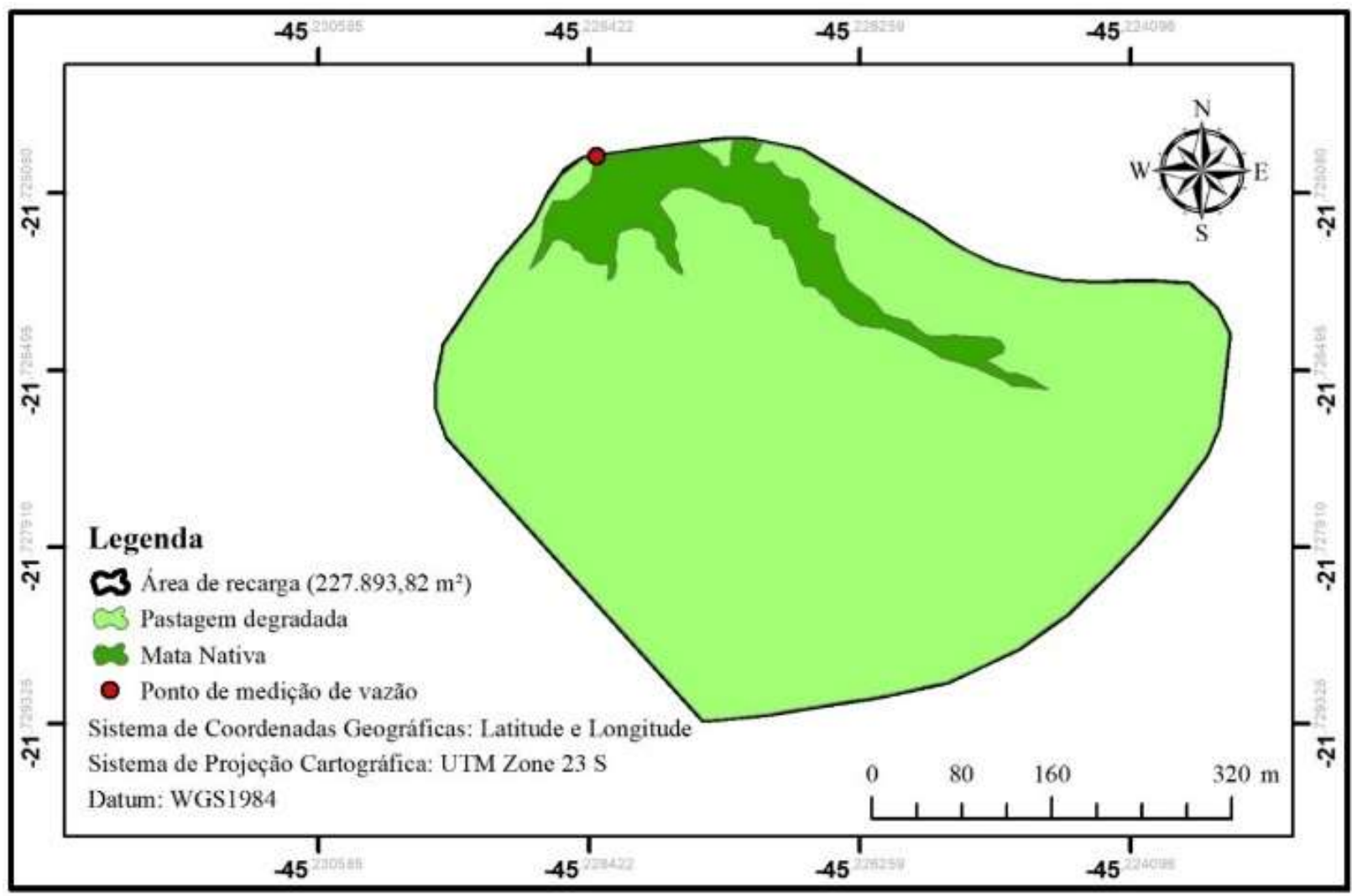

Fonte: Autor (2020).

\subsection{Caracterização do relevo na área de recarga da nascente}

A declividade da área de recarga da nascente variou entre 0 e $45 \%$, apresentando como relevo predominante o ondulado em $83,20 \%$ da área. A classe de relevo com menor expressão é o relevo plano em apenas $0,47 \%$. A declividade média da área é de $15,16 \%$. A altitude varia entre 847 e 979 m, apresentando a média de 935,8 m (Tabela 1). Na Figura 3 é apresentada a distribuição espacial das classes de declividade do solo.

Tabela 1 - Classes de declividade do solo segundo a classificação da Embrapa, 1979.

\begin{tabular}{cccc}
\hline Declividade (\%) & Relevo & Área $\left(\mathbf{m}^{\mathbf{2}}\right)$ & $\mathbf{\%}$ \\
\hline $0-3$ & Plano & 1064,51 & 0,47 \\
$3-8$ & Suave-ondulado & 14255,9 & 6,26 \\
$8-20$ & Ondulado & 189617,05 & 83,20
\end{tabular}




\begin{tabular}{cccc}
$20-45$ & Forte-ondulado & 22956,36 & 10,07 \\
\hline Total & & $227.893,82$ & 100 \\
\hline
\end{tabular}

Fonte: Autor (2020).

O relevo predominante na área (ondulado $-83,20 \%$ ) aliado ao uso do solo, pastagem degradada $(91,98 \%)$, contribui de maneira negativa no tocante ao processo de infiltração e recarga do lençol freático. Nesta situação, há predominância do escoamento superficial direto em relação aos demais processos (infiltração e recarga do lençol freático), reduzindo drasticamente o tempo de oportunidade para o processo de infiltração da água no solo, recarga do lençol freático e, posteriormente, vazão regularizada ao longo do tempo na área da nascente F1.

Alguns trabalhos obtiveram conclusões semelhantes com Oliveira et al. (2014); Menezes (2007) que trabalhando em áreas de recarga de nascentes na região da Serra da Mantiqueira observaram que o uso e cobertura da terra como pastagem degradada associados com declividades elevadas favoreciam o processo de escoamento superficial direto em detrimento aos processos de infiltração e recarga do lençol freático, reduzindo a vazão ao longo do ano hidrológico. 
Figura 3 - Distribuição espacial das classes de declividade do solo para a área de recarga da nascente F1 segundo a classificação da Embrapa, 1979.

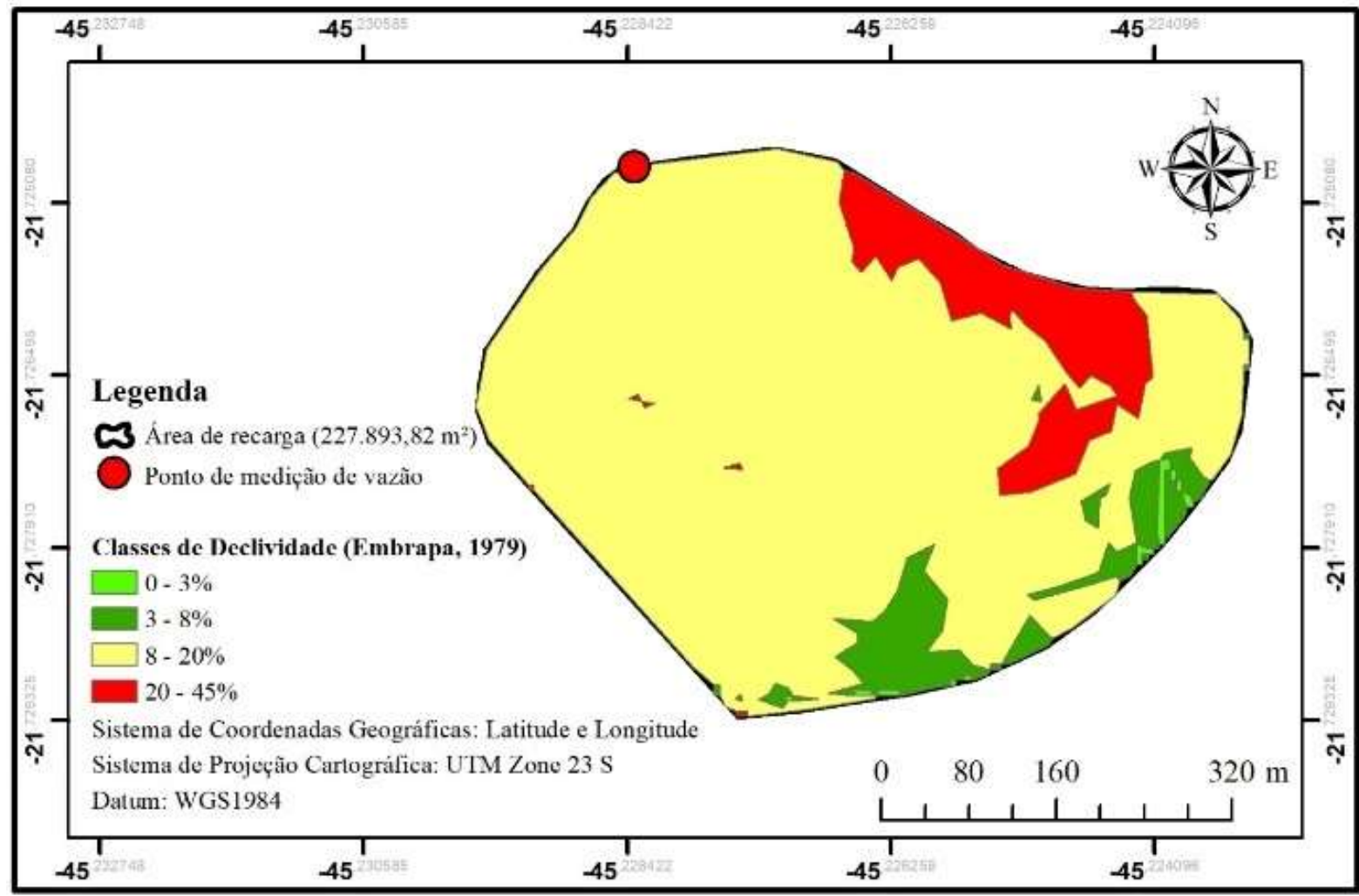

Fonte: Autor (2020).

\subsection{Modelagem da Vazão no Período de Depleção}

Na Tabela 2 são apresentados o deflúvio base no período de depleção, a vazão média e a vazão específica. Foi observado um deflúvio de $22,48 \mathrm{~mm}$ no período de depleção, ou seja, no período em que a contribuição da precipitação no processo de recarga é pouco expressiva. A vazão média foi de apenas 0,40 I.s s $^{-1}$ e a vazão específica igual a $0,081 . \mathrm{s}^{-1}$. 0 baixo deflúvio e a consequente vazão são reflexo da combinação do uso do solo e do relevo, que contribuíram negativamente para a recarga do lençol freático, refletindo na drenagem da nascente.

Oliveira et al. (2014), analisaram a dinâmica do escoamento em quatro nascentes inseridas no ambiente da Serra da Mantiqueira e concluíram que as nascentes cujas áreas de recarga apresentavam o predomínio de pastagem também apresentaram os menores deflúvios e, consequentemente, vazões, corroborando para os resultados obtidos neste trabalho. 
Tabela 2 - Valores característicos do escoamento no período de depleção.

\begin{tabular}{cccc}
\hline \multirow{2}{*}{ Nascente } & Deflúvio base (Db) & Q média & Q específica \\
\cline { 2 - 4 } & $(\mathrm{mm})$ & $\left(\mathbf{l . \mathrm { s } ^ { - 1 } )}\right.$ & $\left(\mathbf{I . \mathrm { s } ^ { - 1 } \cdot \mathrm { ha } ^ { - 1 } )}\right.$ \\
\hline F1 & 22,48 & 0,4 & 0,018 \\
\hline
\end{tabular}

Fonte: Autor (2020).

A Tabela 3 e a Figura 4 apresentam informações sobre o período de depleção da vazão e a respectiva equação, relação entre $Q_{t} / Q_{t o}$ e deflúvio estimado.

Tabela 3 - Parâmetros característico no período de depleção.

\begin{tabular}{cccccc}
\hline Nascente & $\boldsymbol{\alpha}\left(\mathrm{dia}^{-1}\right)$ & $\mathbf{Q}_{\mathrm{to}(06 / 04)}$ & $\mathbf{Q}_{\mathbf{t}(06 / 09)}$ & $\left(\mathbf{Q}_{\mathrm{t}} / \mathbf{Q}_{\mathrm{to}}\right)$ & $\mathrm{Db}(\mathbf{m m})$ \\
\hline F1 & $-0,02211$ & 1,35 & 0,07 & 0,052 & 22,30 \\
\hline
\end{tabular}

Fonte: Autor (2020).

A vazão no início do período de recessão (Qt0), que reflete a influência do período de recarga que o antecede, foi de 1,35 I.s ${ }^{-1}$ e a vazão no fim do período de depleção Qt foi de 0,07 I.s ${ }^{-1}$. Quando se analisa a relação $Q_{t} / Q_{t 0}$, que foi de 0,052 , fica evidente a baixa capacidade de recarga da área da nascente, visto que este valor significa que a vazão no final do período de depleção, ou seja, no período de seco, é de apenas 5,20\% da vazão no início do mesmo período, mostrando grande amplitude de variação. Esta relação caracteriza baixa capacidade de regularização da vazão ao longo do tempo.

Em relação ao coeficiente de decaimento da vazão com o tempo $(\alpha)$, quanto maior este coeficiente, maior a variação da vazão ao longo do tempo, fato também identificado por Oliveira et al. (2014). Este coeficiente mantém relação com o uso e cobertura da terra. Áreas com vegetação de grande porte, quando comparadas a áreas com pastagem degradada, apresentam menores valores deste coeficiente, indicando maior regularização da vazão, ou seja, a diferença entre a vazão no início do período de depleção e no final é pequeno. 
Figura 4 - Curva de depleção da vazão na área de recarga da nascente F1.

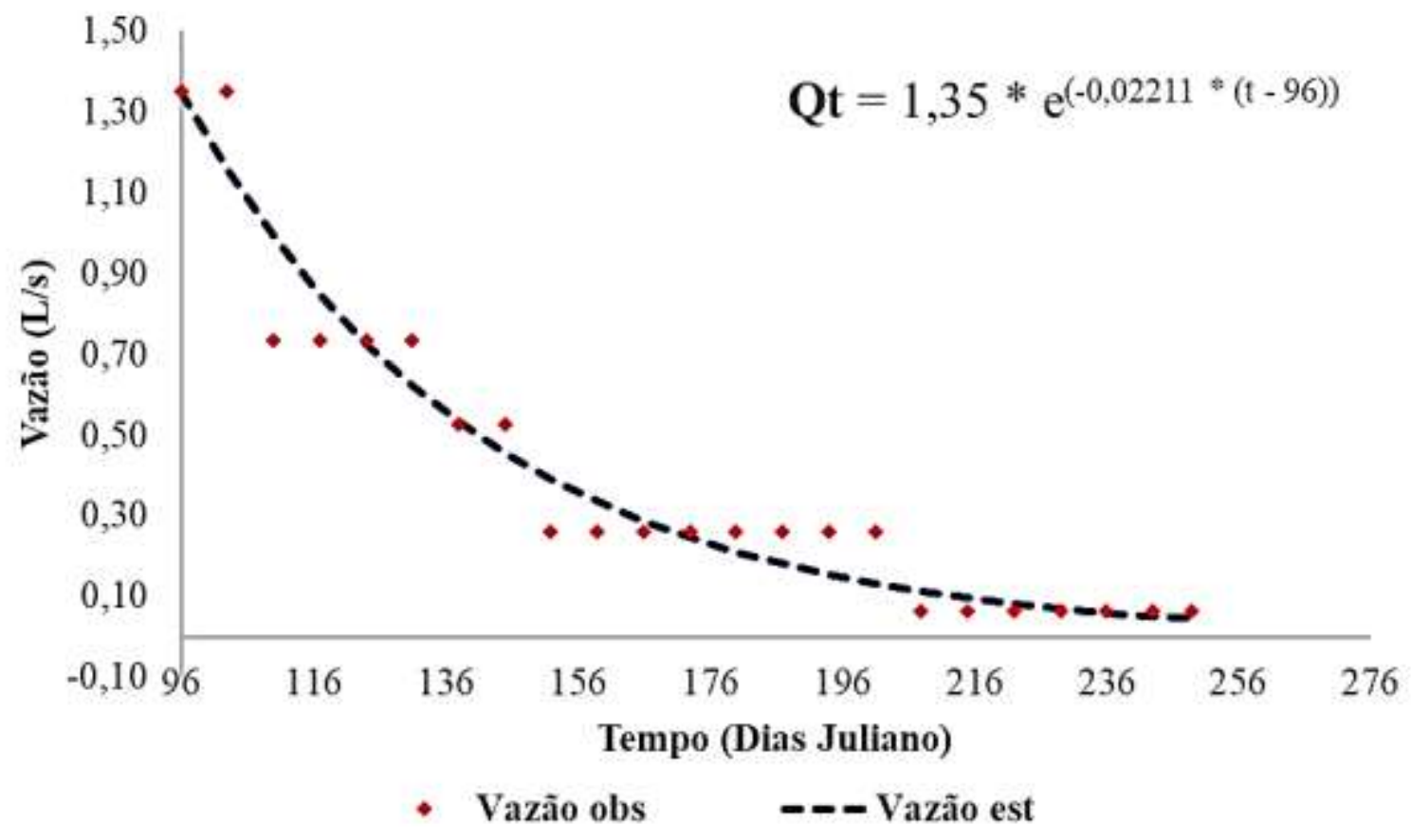

Fonte: Autor (2020).

O deflúvio para o período de depleção apresentado na Tabela 3, estimado com base na equação gerada, quando comparado com o apresentado na Tabela 2 mostra um ajuste adequado, pois o desvio entre os valores está na ordem de $0,8 \%$.

\subsection{Análise do escoamento - Deflúvio}

Na Figura 5, é apresentado o comportamento do deflúvio e da precipitação ao longo do período de monitoramento. Os deflúvios mínimo e máximo quantificados foram respectivamente de 0,46 e 34,57 mm, demonstrando elevada amplitude de variação, significando uma baixa capacidade de regularização natural da vazão na área de recarga desta nascente. Conforme já mencionado, a elevada declividade da área de recarga aliado ao uso do solo, contribuem para a baixa capacidade de armazenamento da água e, consequentemente, na manutenção da vazão ao longo do tempo.

Resultados semelhantes foram encontrados por Oliveira et al., (2014) trabalhando com nascentes na região da Serra da Mantiqueira. Os autores observaram que aquelas nascentes que se encontravam sob o uso e cobertura da terra de pastagem degradada associado à declividades do solo elevadas apresentavam baixa regularização das vazões. 
O deflúvio médio foi de $6,12 \mathrm{~mm}$, o que não representa a realização do escoamento na área de recarga da nascente pois, na maioria do tempo, os valores monitorados estão bem abaixo do valor médio. Este fato demonstra que provavelmente a área de recarga desta nascente tem baixa capacidade de armazenamento e retenção da água no solo e que a pouca água armazenada durante o período chuvoso é rapidamente drenada, contribuindo para elevação do deflúvio médio.

Entre os meses de setembro e o início de dezembro, ocorreu um total precipitado de $354,5 \mathrm{~mm}$ equivalendo a $38,15 \%$ do total precipitado no período de monitoramento. Apesar do volume precipitado, não houve uma resposta significativa em relação à elevação do deflúvio. Fato que pode ser explicado pela deficiência inicial de umidade do solo devido ao longo período de estiagem aliado ao uso e cobertura da terra de pastagem degradada e à elevada declividade na área. A interação destes fatores contribui para a redução do tempo de oportunidade para que a água infiltre no solo e, consequentemente, não contribui para a recarga do lençol freático e regularização do escoamento base.

Figura 5 - Deflúvio base e precipitação na área de recarga da nascente F1 no ano 2019/2020.

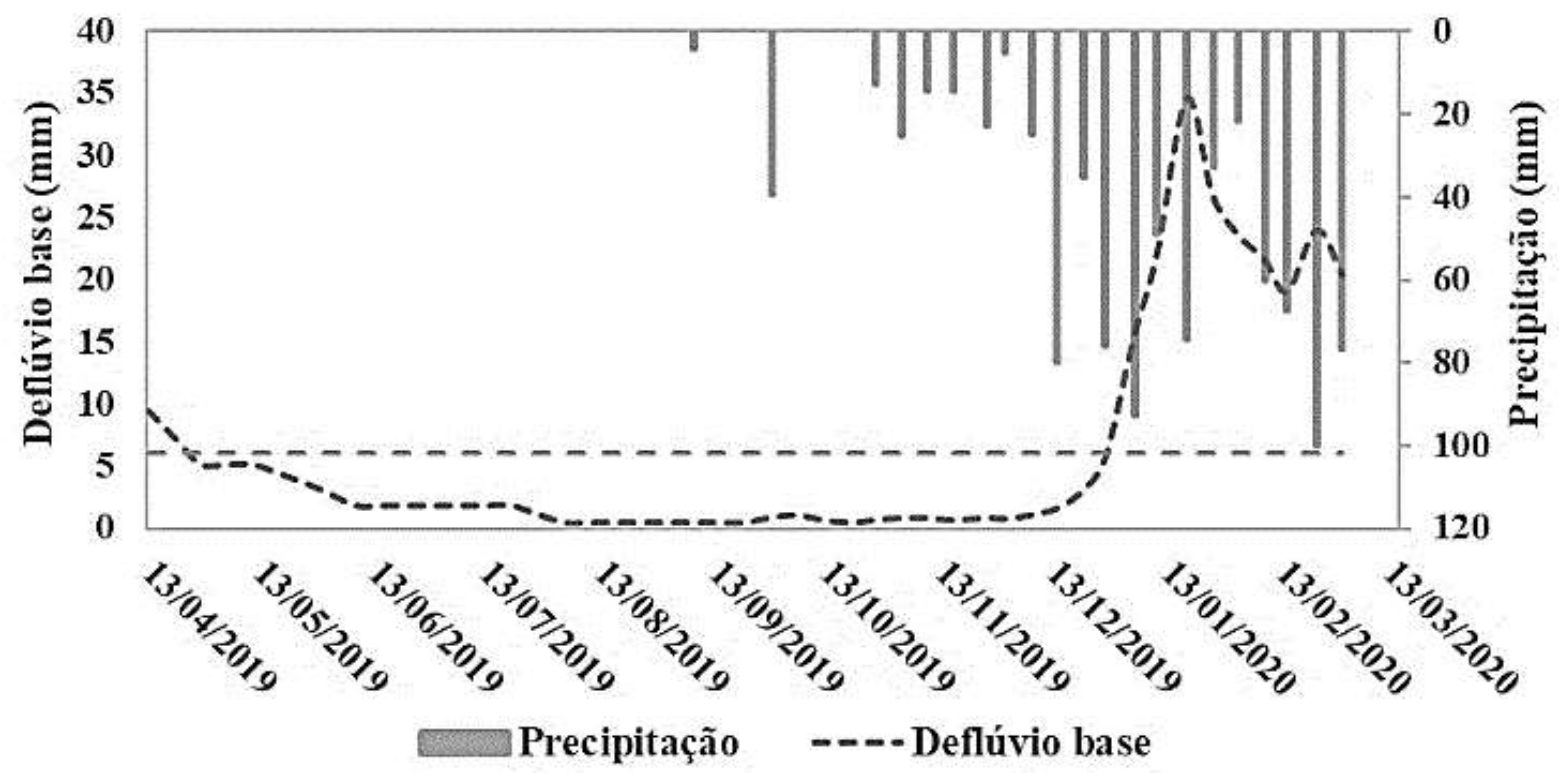

Fonte: Autor (2020).

Na Tabela 4 é apresentado a síntese da análise do escoamento, onde se pode verificar que o deflúvio total anual para o período analisado foi de $108,99 \mathrm{~mm}$. Deste total, $79,37 \%(86,51 \mathrm{~mm})$ ocorreram no período de recarga e o restante $(20,63 \%=22,48 \mathrm{~mm})$ no 
período de depleção. O ideal seria uma distribuição uniforme do deflúvio ao longo do ano e não concentrado em um período específico.

Tabela 4 - Síntese da análise do escoamento na área de recarga da nascente F1.

\begin{tabular}{cccccc}
\hline & \multicolumn{3}{c}{ Deflúvio base (Db) } & Vazão (Q) & \multirow{2}{*}{ Q específica } \\
\cline { 2 - 5 } Nascente & Anual & Recarga & Depleção & média anual & \\
\cline { 2 - 5 } & $(\mathrm{mm})$ & $(\mathrm{mm})$ & $(\mathrm{mm})$ & $\left(\mathrm{I.s^{-1 } )}\right.$ & $\left(\mathrm{l} . \mathrm{s}^{-1} \cdot \mathrm{ha}^{-1}\right)$ \\
\hline \multirow{2}{*}{ F1 } & 108,99 & 86,51 & 22,48 & 0,90 & 0,039 \\
\hline
\end{tabular}

Fonte: Autor (2020).

A vazão média anual é de $0,90 \mathrm{I} \cdot \mathrm{s}^{-1}$ e a vazão específica é de $0,039 \mathrm{I} \cdot \mathrm{s}^{-1}$.ha-1. $\mathrm{O}$ total precipitado no período foi de $929,28 \mathrm{~mm}$ e o deflúvio base igual a 108,99 mm. Quando se analisa a participação do deflúvio base (Db) no total precipitado $(P)$, este valor foi de apenas $11,73 \%$, correspondendo à parcela que realmente infiltrou e contribuiu com a geração de escoamento base. Este indicador é muito útil no contexto da recarga uma vez que expressa a capacidade da bacia em termos de armazenamento de água na zona saturada. Em condições ideais, espera-se uma relação Db/P entre 20 e $30 \%$.

\section{DISCUSSÃO}

\subsection{Caracterização do Uso e Cobertura da Terra na área de recarga da nascente}

Hidrologicamente, o processo de recarga do lençol freático é reduzido drasticamente em áreas com predomínio de pastagem degradada, visto que ocorre um maior escoamento superficial direto, diminuindo o tempo de oportunidade para que a água sofra o processo de infiltração e consequente recarga. Resultados obtidos por Gaspar, Campos e Cadamuro (2007), corroboram com esta afirmação. No trabalho, avaliaram o potencial de infiltração de água no solo em diferentes usos e concluíram que dentre os usos que proporcionam as menores taxas de infiltração se encontra a pastagem degradada.

A distribuição desuniforme de mata nativa na área de recarga da nascente, além de não contribuir eficientemente para o processo de recarga do lençol freático, não é capaz de 
impedir a entrada de sedimentos próximo à surgência da nascente, fato observado em campo.

Vale ressaltar que se tratando de pastagem bem manejada, devido à redução da evapotranspiração e revolvimento do solo em sua implantação, pode-se, em termos anuais, haver um aumento do deflúvio, principalmente em regiões onde predominam precipitações de baixa intensidade, conforme observado por Salemi et al., (2012) estudando os impactos da conversão de área de floresta tropical pluvial atlântica em área de pastagem bem manejada.

\subsection{Caracterização do relevo na área de recarga da nascente}

A predominância do relevo ondulado aliado ao uso do solo, pastagem degradada contribuem de maneira negativa no tocante ao processo de infiltração e recarga do lençol freático. Nesta situação, há predominância do escoamento superficial direto em relação aos demais processos (infiltração e recarga do lençol freático), reduzindo drasticamente o tempo de oportunidade para o processo de infiltração da água no solo, recarga do lençol freático e, posteriormente, vazão regularizada ao longo do tempo na área da nascente F1.

Alguns trabalhos obtiveram conclusões semelhantes com Oliveira et al. (2014); Menezes (2007), que trabalhando em áreas de recarga de nascentes na região da Serra da Mantiqueira e observaram que usos e cobertura da terra como pastagem degradada associados com declividades elevadas favoreciam o processo de escoamento superficial direto em detrimento aos processos de infiltração e recarga do lençol freático, reduzindo a vazão ao longo do ano hidrológico.

\subsection{Modelagem da vazão no período de depleção}

O baixo deflúvio e a consequente vazão são um reflexo da combinação do uso do solo e relevo que contribuíram negativamente para a recarga do lençol freático, refletindo na drenagem da nascente.

Silva et al. (2018), realizando a caracterização hidrológica em 8 nascentes inseridas em dois ambientes distintos, Serra da Mantiqueira e Alto do Rio Grande, observaram que aquelas nascentes cujas áreas de recarga ocorre a predominância de pastagem degradada, 
de maneira semelhante apresentaram os menores deflúvios e consequentemente, vazões, corroborando com os resultados obtidos neste trabalho.

Quando se analisa a relação $Q_{t} / Q_{t 0}$, que foi de 0,052 , fica evidente a baixa capacidade de recarga da área da nascente. Esta relação caracteriza baixa capacidade de regularização da vazão ao longo do tempo. Em relação ao coeficiente de decaimento da vazão com o tempo $(\alpha)$, quanto maior este coeficiente, maior a variação da vazão ao longo do tempo, fato também identificado por Silva et al, (2018). Este coeficiente mantém relação com o uso e cobertura da terra, onde áreas de recarga com vegetação de grande porte apresentam menores valores deste coeficiente, indicando maior regularização da vazão, ou seja, a diferença entre a vazão $Q_{t}$ e $Q_{t o}$ é pequena.

\subsection{Análise do escoamento - Deflúvio}

O deflúvio médio foi de 6,12 $\mathrm{mm}$, o que não representa a realidade do escoamento na área de recarga da nascente pois, na maioria do tempo, os valores monitorados estão bem abaixo do valor médio. Este fato pode estar relacionado ao uso e cobertura da terra e pastagem degradada associada à elevada declividade da área (predominância do relevo ondulado), contribuindo negativamente para o processo de infiltração e, consequentemente, para a recarga do lençol freático e geração de deflúvio. Alvarenga et al. (2012), trabalhando com um índice de qualidade do solo associado à recarga de água subterrânea (IQS $S_{\mathrm{RA}}$ ) em bacias hidrográficas na região do Alto Rio Grande, observaram que nas áreas com uso e cobertura do solo com vegetação nativa, quando comparadas a áreas com pastagem degradada, a vegetação nativa contribuiu de maneira positiva para a geração de deflúvio.

\section{CONCLUSÕES}

O uso e cobertura do solo predominante na área de recarga da nascente F1 é a pastagem degradada (91,98\%). O relevo predominante é o ondulado em $83,20 \%$, com uma declividade média de 15,16\% e altitude média de 935,8m.

A vazão no início do período de depleção $\left(Q_{t}\right)$ foi de 1,35 L/s e no final do período $\left(Q_{t 0}\right)$ foi de $0,07 \mathrm{~L} / \mathrm{s}$. Fica evidente a influência negativa do uso e cobertura da terra 
associado à declividade elevada na geração do escoamento, fatos comprovados com a relação $Q_{t} / Q_{\text {to }}$ de apenas 5,20\%, aliados ainda ao coeficiente de depleção $\alpha$ igual a -0,02211.

A precipitação total no período analisado foi de $929,28 \mathrm{~mm}$, o deflúvio total igual a 108,99 mm e a participação do deflúvio base no total precipitado (Db/P) foi de 11,73\%.

\section{AGRADECIMENTOS}

Ao programa PBIICT/UninCor pela concessão da bolsa de iniciação científica.

\section{REFERÊNCIAS}

ALVARENGA, A. P. et al. Sobrevivência e crescimento inicial de espécies arbóreas nativas na restauração de nascentes no Sul de Minas Gerais. Enciclopédia BIOSFERA Centro Científico Conhecer - Goiânia, Goiânia, v. 13, n. 23, p. 1239-1250, 2016.

ALVARENGA, C. C. et al. Índice de qualidade do solo associado à recarga de água subterrânea (IQSRA) na bacia hidrográfica do Alto Rio Grande, MG. Revista Brasileira de Ciência do Solo, Viçosa, v. 36, n. 5, p. 1608-1619, nov. 2012.

BRASIL. Lei no 12.651, de 25 de maio de 2012. Dispõe sobre a proteção da vegetação nativa; altera as Leis nos 6.938, de 31 de agosto de 1981, 9.393, de 19 de dezembro de 1996, e 11.428, de 22 de dezembro de 2006; revoga as Leis nos 4.771, de 15 de setembro de 1965, e 7.754, de 14 de abril de 1989, e a Medida Provisória no 2.166-67, de 24 de agosto de 2001; e dá outras providências. Brasília, DF: Presidência da República, 2012.

COHENCA, D.; CARVALHO, R. Comparação de métodos de classificação OBIA, máxima verossimilhança e distância mínima em imagem OLI/Landsat-8 em área de alta diversidade de uso do solo. In: SIMPÓSIO BRASILEIRO DE SENSORIAMENTO REMOTO - SBSR, 17., João Pessoa. Anais [...]. João Pessoa: INPE, 2015.

CASTANY, G. Traité pretiquedes eaux souterraines. 2. ed. Paris: Dunod, 1967.

COSTA, F. M.; BACELLAR, A. P. Caracterização hidrogeológica de aquíferos a partir do fluxo de base. Revista Brasileira de Recursos Hídricos, Ouro Preto, v. 15, n. 3, p. 173-183, jul./set. 2010.

DIAS, L. S. O. et al. Utilização do radar interferométrico para delimitação automática de bacias hidrográficas. Bahia Análise \& Dados, Salvador, v. 4, n. 2, p. 265-271, set. 2004.

GASPAR, M. T. P.; CAMPOS, J. E. G.; CADAMURO; A. L. M. Condições de infiltração em solos na região de recarga do sistema aquífero Urucuia no oeste da Bahia sob diferentes condições de usos. Revista Brasileira de Geociências, [S. I.], v. 37, n. 3, p. 542-550, set. 2007. 
GOMES, F. C. E. et al. A nova legislação ambiental brasileira e seus efeitos sobre a reestruturação de nascentes e remanescentes florestais. Pesquisa Florestal Brasileira, Colombo, v. 38, p. 1-10, 2018.

SILVA, A. L. et al. Caracterização hidrológica de nascentes de sub-bacias hidrográficas na região do Alto Rio Grande, MG. Revista Agrogeoambiental, Pouso Alegre, v. 10, n. 3, set. 2018.

LEAL, M. S. et al. Caracterização hidroambiental de nascentes. Rev. Ambient. Água, [S. I.], v. 12, n. 1, p. 146-155, 2017.

MENEZES, M. D. Levantamento de solos em bacias hidrográficas como apoio para avaliação do uso da terra e da potencialidade de recarga dos aquíferos. 2007. 107 p. Dissertação (Mestrado em Ciência do Solo) - Universidade Federal de Lavras, Lavras, 2007.

OLIVEIRA, A. S. et al. Streamflow regime of springs in the Mantiqueira mountain range region, Minas Gerais State. CERNE, [S. I.], v. 20, p. 343-349, 2014.

SALEMI, L. F. et al. Consequências hidrológicas da mudança de uso da terra de floresta para pastagem na região da floresta tropical pluvial atlântica. Ambi-Agua, Taubaté, v. 7, n. 3, p. 127-140, 2012.

SOBRINHO, T. A. et al. Delimitação automática de bacias hidrográficas utilizando dados SRTM. Engenharia Agrícola, Jaboticabal, v. 30, n. 1, p. 46-57, jan./fev. 2010.

USAE. Engineering and design - groundwater hydrology. Washington: Department of the Army: US Army corp sof Engineers, 1999. 